\title{
Software Engineering Days: Using a Video Game Platform to Teach COLLABORATIVE SOFTWARE DEVELOPMENT
}

\author{
Chris Rennick, Derek Rayside, John Harris, and Patrick Lam \\ University of Waterloo \\ crennick@uwaterloo.ca,drayside@uwaterloo.ca,john.harris@uwaterloo.ca, and \\ patrick.lam@uwaterloo.ca
}

\begin{abstract}
This paper describes the implementation and assessment of a multi-day engineering design activity for Software Engineering students. This activity required students to work in teams of 16 to develop and implement four sub-systems of a digital spaceship. The Unity video game engine with a custom "spaceship sandbox" were used to drive student intrinsic motivation for the task, and to limit the complexity of the spaceship implementation.

Student feedback of the activity was captured through a survey given immediately following the second day of the activity, and through a focus group conducted with four students later in the term. The feedback on the activity was largely positive, with teamwork, collaboration, and the software to accomplish it (Git) as major learning outcomes identified by students. Several improvements are planned for the fall 2019 version of the activity based on both instructor observation and student feedback.
\end{abstract}

Keywords: Design practice, games, team based learning, active learning, software engineering

\section{INTRODUCTION}

The Engineering Ideas Clinic at the University of Waterloo designs and implements hands-on activities that immerse students in real-world problems. In these activities, students need to collaborate to design solutions to ambiguous, open-ended challenges [1]. These challenges integrate the many knowledge domains within a program, support students through a structured design process, and feature tools and equipment that students will use in their future work as engineers, thus improving students' engineering "know-how" [2].

Over the last several years, these activities have predominantly taken the form of Engineering Design Days (Design Days). Design Days are multi-day design sprints where a cohort of students is given a disciplinespecific design challenge to work on in teams over the course of two days (typically 12-16 hours in total).
Students design, construct, and validate their solution to the given challenge (see [3] [4] [5] for descriptions of some these different activities), and are not typically graded for the quality of their final solution, but instead are graded on a reflection of the process they went through. Limiting the academic grades in this way gives students the freedom to try risky solutions and to experience failure. In addition to the high-level goals of these activities, Engineering Days events have shown they are capable of achieving course level learning outcomes [6].

\subsection{Software Engineering}

Software Engineering (SE) at the University of Waterloo is a joint program between the Faculties of Math and Engineering. Software Engineering consists of a single cohort of so-called "8-Stream" students (as they have their first work term after 8 months of academic work). In fall 2018, the class had 120 students enrolled. All of these students had prior high school programming experience as a requirement of admission into the program. In their first semester on campus (the 1A term), these students took three math courses, a course in classical mechanics, a CS1-style university level programming course (CS 137 - Programming Principles), and SE 101 - Introduction to Methods of Software Engineering.

SE 101 is weighted as half of a regular course (a 0.25 credit course at Waterloo) and serves both as an introduction to the engineering profession as well as an introduction to software engineering methods and principles. This course has contained a team-based course project in the second half of the term for many years, but recently, the course instructors have identified some opportunities for improvement in how students transition into the end of term project. To address these, the Engineering Ideas Clinic worked with the course instructors to adapt the Engineering Design Days concept to the Software Engineering domain.

This paper presents the design, implementation, and assessment of the pilot implementation of the Software

CEEA19; Paper 131

University of Ottawa; June 9-12, 2019

-1 of $8-$ 
Engineering Design Days activity with recommendations for future iterations of the event.

\section{SOFTWARE DESIGN DAYS DESCRIPTION}

\subsection{Activity Outcomes}

The Software Engineering program piloted an Engineering Design Days activity in the fall 2018 term to introduce the 1A SE students to multi-person development of multi-version software - one timehonoured definition of "software engineering" given by Brian Randell and David Parnas [7]. It was not intended to teach introductory programming, but instead focussed on the following technical learning objectives:

1. version control software (using Git);

2. prototyping theory: evolutionary vs exploratory; horizontal vs vertical (see [8] for an overview of these concepts);

3. division of labour for large tasks (when to focus design efforts on component integration vs component internals);

4. feature flags (or branches) for managing variants of the software;

5. pair programming; and

6. quickly learning an unfamiliar API (Application Programming Interface).

In addition to these technical objectives, the activity gave students a preview of some of the curriculum to come in their future courses: object-oriented programming (CS 138 + CS 247); Dijkstra's shortestpath algorithm (CS 240); and PID control (SE 380). Additionally, this activity had social objectives of improving cohort cohesion and professional identity.

\subsection{Activity Design}

The Engineering Design Days activity for Software Engineering revolved around an activity built using the Unity real-time video game engine [9]. Students developed a spaceship capable of navigating three progressively more difficult sections of interstellar space. The choice of Unity, a commercially-available and widely-used video game engine sought to improve student motivation and engagement during the activity. Similarly, the concept of building a spaceship was identified early in the planning for this event, as a task that would be interesting to a broad range of students.

To avoid bogging students down in the intricacies of Unity, the activity was carefully crafted to expose a relatively limited API surface into the "spaceship sandbox" while still providing an entertaining and creative learning context. Figure 1 shows a screenshot of the Unity development environment with part of the first section of interstellar space given to students.

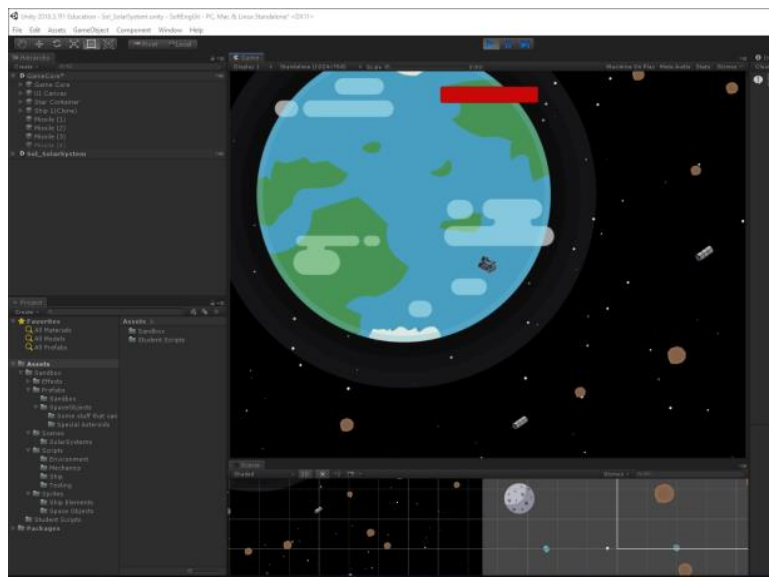

Figure 1 Screenshot of Unity sandbox environment

A key requirement for the activity was that it require (relatively) large teams of students to complete. During a brainstorming session, the development team came up with the idea of splitting the ship into sub-system components. Each sub-system could then have a small team of students working on it. These smaller teams would need to come back together at various points to integrate their individual systems into the whole ship. The following constraints guided the design of the subsystems:

1. the subsystem "problems" should require algorithms that are representative of ones that students might encounter in their program;

2. the problems must be solvable by $1 \mathrm{~A}$ students with an uncontrolled range of prior experience in a limited amount of in-lab time;

3. each of the spaceship's subsystems needed to be a non-trivial programming challenge, but still be understandable and solvable within only a handful of hours; and,

4. the subsystems must require some level of code interaction with peer subsystems, and pay at least minimal lip service to the encompassing spaceship narrative.

Ultimately, the spaceship layout used in the activity consisted of four sub-systems that were required to communicate with at least two other things: either other ship sub-system(s), and/or the ship's "hardware". Figure 2 below shows the layout of the communication connections between the various systems on the ship.

To interface with the ship's hardware, students interacted with data members and "update" methods of 
the pre-built spaceship class. As one example, the students that worked on the propulsion sub-system controlled each thruster (Figure 3 below shows the layout of the ship thrusters), and therefore the position and velocity of the ship, by writing to the appropriate member of the ship class. For example, thrusterControls.mainThrust $=$ (your float); would provide thrust to the main thruster at the back of the ship.

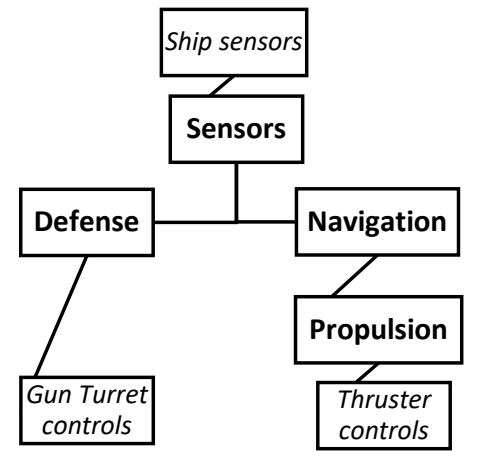

Figure 2 Spaceship sub-system connections

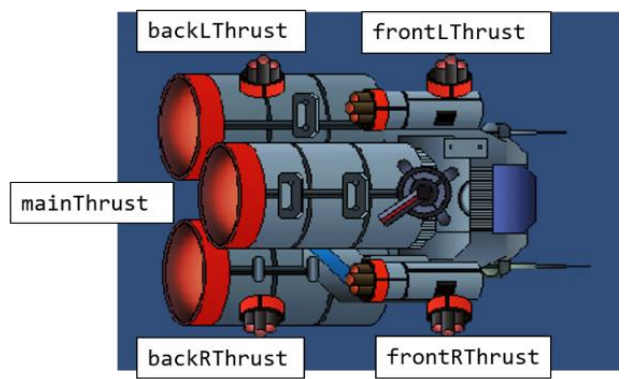

Figure 3 Physical layout of thrusters for propulsion subsystem

For the activity, teams of four students were assigned to each sub-system on the ship, ultimately requiring 16 students to collaborate together on getting their team's ship up and running.

\subsection{Activity Logistics}

The Design Days activity for SE was scheduled over two school days, in the third and fourth weeks of the 12week term. Because Software Engineering at Waterloo is a cohort-based program, students have virtually identical schedules. SE program administration could therefore arrange with instructors for students' classes during the Design Days activity to be rescheduled elsewhere during the term. Program administration also arranged for a large computer lab capable of accommodating 120 students working in groups.

Before class, the instructional team randomly divided the students into large groups of 16, which could then be split into 4 subgroups (one per subsystem). Students were provided with their team memberships on the day of the activity. The computer lab was in a tiered amphitheatre-style classroom with moveable chairs and desks comfortably accommodating 3 students (or 4 uncomfortably), so that an entire team could fit in 4 rows.

On the first day of the activity, a member of the instructional team presented an introductory lecture of about an hour, teaching the concepts of multi-person development of multi-version programs, along with introductions of pair programming, and configuration management. This lecture introduced the activity and proposed an iterative approach where subgroups would rotate frequently among the subsystems. Table 1 below shows the suggested progression of tasks for each subsytem.

As for any software development task, students needed to get their software environments set up (viz. Unity and Git). The on-site instructional team (instructors and $3 \mathrm{TAs}$ ) attempted to provide tutorials so that students could install necessary software ahead of time, but still needed to help a number of students with their setup. While Unity was available on the computers

Table 1 Spaceship sub-system task progression

\begin{tabular}{|c|c|c|c|c|}
\hline Task & Sensors & Navigation & Propulsion & Defence \\
\hline 0 & \multicolumn{4}{|c|}{ Install Git \& Unity } \\
\hline \multicolumn{5}{|l|}{ Rotate Pairs/Squads } \\
\hline \multirow[t]{2}{*}{1} & \multicolumn{4}{|c|}{ Determine Interfaces } \\
\hline & Report fake objects & $\begin{array}{l}\text { Go to first visible } \\
\text { warpgate }\end{array}$ & $\begin{array}{l}\text { Use UFO drive to reach } \\
\text { desired destination }\end{array}$ & $\begin{array}{l}\text { Demonstrate firing in } \\
\text { multiple directions }\end{array}$ \\
\hline \multicolumn{5}{|l|}{ Rotate Pairs/Squads } \\
\hline 2 & $\begin{array}{l}\text { Filter/clean data, pass } \\
\text { to peer subsystems }\end{array}$ & $\begin{array}{l}\text { Hard-code Wikipedia } \\
\text { solution to Djiksta graph }\end{array}$ & $\begin{array}{l}\text { Implement PD control } \\
\text { for directed thrusters }\end{array}$ & $\begin{array}{l}\text { Repeatedly destroy } \\
\text { nearest obstacle }\end{array}$ \\
\hline \multicolumn{5}{|l|}{ Rotate Pairs/Squads } \\
\hline 3 & & $\begin{array}{l}\text { Implement Djikstra's } \\
\text { algorithm }\end{array}$ & $\begin{array}{l}\text { Minimize fuel costs (i.e. } \\
\text { parking on top of warp } \\
\text { gates before jump) }\end{array}$ & $\begin{array}{l}\text { Intelligently destroy } \\
\text { obstacles while } \\
\text { conserving ammo }\end{array}$ \\
\hline
\end{tabular}

CEEA19; Paper 131

University of Ottawa; June 9-12, 2019
-3 of $8-$ 
in the lab, most students preferred to work on their own laptops, slowing down the start of the activity.

During the activity, the instructional staff circulated in the room, observed students at work, and provided support. The Engineering Ideas Clinic and Software Engineering program administration provided lunch for the students to promote increased social interaction.

The lab was available for about 6 hours on each day, although students left before the end of the day. To limit the impact of the activity on the other courses in the term, students were asked to not work on the exercise at home. The exercise was also carefully scoped for two in-class days, and so a week of effort was not required. At the end of the second day, groups were encouraged to demonstrate their spaceship.

\section{RESULTS}

Two steps were taken to assess the impact of the activity: a survey was administered immediately following the event, and an hour-long focus group was conducted near the end of term with a group of four first year students who participated in the event.

\subsection{Survey Results}

The survey asked students to respond to a series of three open text questions. The first asked students what they learned from the event; the second asked what they would improve in future offerings; and the third asked questions relating to the space used for the activity. A thematic analysis on these responses identified any patterns across the student cohort. For brevity and clarity, only the analysis of students' responses to the first two questions will be presented here.

Table 2 below summarizes the categories used to code question 1 of the survey if they were mentioned by more than one student (the bolded phrases) with related codes (the words/phrases beginning with a plus sign). From these data, many students agreed that they learned about using Git, and that they learned to work in teams/collaborate with others. A more limited number of students also commented on learning software engineering principles. Comments mentioned by only one student were diverse in nature, and included learning about the necessity of leadership, integration testing, proper commenting, and team motivation. Individual students also mentioned learning about using the command line, and Unity.

Table 3 below summarizes the categories used when coding question two of the survey. Again, responses in the table are limited to those that were mentioned by more than one student. From these data, many students felt that the sessions were too long, and that they would like to split the activity over more than two days. Many would like more documentation, more guidance, and/or more instruction on object-oriented programming or using the Unity environment. Students also commented that there were some issues with disengagement and/or people leaving the activity early.

Table 2 Thematic analysis of responses to question 1 ("what did you learn?") of post-event survey. Bolded entries denote major item categories

Q1: What did you learn? \# of

\begin{tabular}{|l|r|}
\hline git & mentions \\
\hline teamwork & $\mathbf{3 5}$ \\
\hline + communication & $\mathbf{2 0}$ \\
\hline collaboration & $\mathbf{1 9}$ \\
\hline pair programming & $\mathbf{1 5}$ \\
\hline $\begin{array}{l}\text { + letting less-experienced person } \\
\text { drive }\end{array}$ & 2 \\
\hline software engineering & \\
\hline + [continuous] integration & 5 \\
\hline + using git issues (aka bug reporting) & 3 \\
\hline $\begin{array}{l}\text { + experimental vs evolutionary } \\
\text { prototypes }\end{array}$ & 2 \\
\hline + iterations & 2 \\
\hline
\end{tabular}

Table 3 Thematic analysis of responses to question 2 ("what would you improve?") of post-event survey. Bolded entries denote major item categories

\begin{tabular}{|l|r|}
\hline Q2: What would you improve? & $\begin{array}{l}\text { \# of } \\
\text { mentions }\end{array}$ \\
\hline more sessions, each shorter & 14 \\
\hline more guidance & 13 \\
\hline documentation / more info for prep & 11 \\
\hline more enforced iteration structure & 9 \\
\hline Object-oriented/unity programming & 8 \\
\hline dealing with disengagement & 7 \\
\hline + incentive to stay till end & 2 \\
\hline have smaller teams & 7 \\
\hline vs. Fewer spaceships, more subteams & 2 \\
\hline less complex program to work on & 5 \\
\hline vs. More complex program to work & 2 \\
\hline on & 4 \\
\hline more TA interaction & 2 \\
\hline less dependent on C\# & 2 \\
\hline lower barrier to contribute & \\
\hline
\end{tabular}

The last two categories of comments had some disagreement between students. Some wanted smaller teams, while others wanted the ships to have more subsystems, which would require the overall size of the team to grow to match. Similarly, some students wanted to work on a less complex problem, while others wished 
it were more complex. As with the first survey question, the issues mentioned by only one student were highly diverse and ranged from "have more food available", to attaching additional grades to the activity. While there are more people asking for smaller teams and less complex programs to work on, the disagreement and relatively limited numbers likely indicate the activity achieved a good compromise for most.

The student responses to the third survey question pointed to some issues with the space used for the activity, especially as it related to their (in-)ability to collaborate with their teammates.

\subsection{Focus Group Results}

A focus group was conducted with four members of the 1A Software Engineering cohort in week 11 of the term. This focus group was conducted by a member of the Engineering Ideas Clinic, who oversaw the early development of the activity. This facilitator was therefore at an arm's length from the students' academics, while still being familiar with the activity. The focus group was conducted using a semi-structured set of questions over approximately 80 minutes in total. The original facilitator of the focus group transcribed the audio recording, and conducted the analysis of student responses.

The students had several positive things to say about the activity, many of which reinforced the feedback received from the post-event survey. One student, when asked about extra-curriculars they were taking part in, described the value of the spaceship activity for showing the diversity of software engineering:

Student 1: [P]articipating in clubs and that sort of thing is a good way to know that you won't regret your university career in the future because you've tried it out and you know that it isn't for you... I think that's why things like the Ideas Clinic are really valuable because you can find out specifically what you like in the coop field that you might be going into.

Later in the focus group, a different student reinforced that the activity felt like a realistic software development task that would help them during their future work terms:

Student 4: It felt realistic. It felt way more realistic than what we could have experienced throughout the entire academic term, because most of it is just we go to class, they teach us stuff, we take it down in our notes, then we go home and study. So, compared with those things, it was way more realistic... So I think where it really helped us a lot is in applying for jobs.

The students also appreciated the diversity of subtasks that were required for the ship, with one student wishing the ship were more complicated with more subsystems. This advantages of this diversity of tasks was felt very keenly by one student, who was very challenged in the first day. During day two, this student found a task that better aligned with their strengths:

Student 2: [For] the defense systems, the programming wasn't too hard, but there was quite a bit of physics, and I think I was really skilled in physics, so while it was a challenge, I guess it was digestible from the programming aspect

As with the survey responses, teamwork and collaboration were strengths of the activity. Two of the four students in the focus group felt the spaceship activity allowed them to get to know their classmates better:

Student 1: I got to learn my cohort really well. I got to know the students in my cohort.

Student 3: Also, adding to that, we not only observed the diversity and the difference in knowledge and skills, you could also see their personalities come out. You could see how people would work in a team, and how they would perform in a team environment

Not all of the feedback was positive. Two of the students (Students 2 and 4) had a much less collaborative team than the other two (who happened to work together during the activity). Student 2 in particular struggled to contribute individually on day one, felt less connected to their teammates, and therefore did not enjoy the activity as much.

Student 2: From my own experience, ... at least in the first day, I didfeel like my time was being wasted in a fruitless attempt to just get version control in Unity working well, while everybody else [found it easy]

This frustration was ultimately too much for Student 2's partner on the first day, who had enough and left:

Student 2: Also, I can say from experience that my partner was... became somewhat apathetic after everything started to sort of not work out, and [they] eventually just left, and I was left on my own.

Where Student 1 - who was a very experienced programmer - helped organize their team, and supported their teammates, student 2 developed few connections to their teammates:

Student 2: in my experience, I didn't even know or speak to a lot of the people in my team. The same probably goes for a lot of people. When we did the group planning session, a lot of people just kept silent, and then there was no further interaction

Interviewer: A half hour ago we talked about this activity giving an opportunity to get to know your cohort, it sounds like you didn't get that outcome?

Student 2: no, it seemed like everyone was just cloistered in their [sub-] teams to the point where we 
couldn't really have much interaction with the other teams.

Student 2 ultimately persisted with the activity, and as described earlier, enjoyed the second day more when they found a task that aligned better with their strengths. Unfortunately, the relationships with their teammates did not improve on the second day:

Student 2: the second day Ifeel like it was better for me personally, [but] the communication in my group deteriorated further, so there were some people who were essentially absent the second day ... Some of them just never bothered to even communicate in the second day, it was like, we all just did our things and then at the end, there was a... half-hearted attempt to throw everything together

The students had many constructive suggestions to improve the activity for the future. The first set of recommendations that came up in the focus group suggested that additional preparatory work should happen in advance of the activity. The students suggested two tasks to conduct before the activity: a short team-building exercise, and basic instruction on Unity and Git. One student felt that separating this work from the main activity would improve everyone's experience of the event:

Student 1: to go back to what you mentioned about unity and pre-installing, it's valuable to have... it doesn't take too long to do a session, or even like send them to a tutorial on youtube... of setting up Unity on a Windows system and starting the sandbox environment... There's a lot of information thrown at you at the same time, and I think separating it into setting up your [programming] environment, setting up your [team] management, and now you can get into the nitty gritty of the actual fun stuff in the engineering clinic.

The students also felt that two 6-hour days with a week in between was too long, and may have been overwhelming for some of their peers. They suggested that splitting the 12 contact hours over more days would improve engagement, give people a chance to catch their breath and address personal shortcomings (knowledge, skill, or otherwise), and so could prevent students from walking out of the activity early. Lastly, while there was disagreement between the students in the focus group, several felt it was important for individuals to have personal goals, in addition to the team goal of getting the spaceship working. When discussing the topic, the students felt that these personal goals should be discussed with their teammates, and that a pre-event team-building exercise could provide a good time to do so.

\section{DISCUSSION}

Each student subsystem team ultimately needed to implement a single per-frame "update" method (and could optionally provide interfaces for their peer subsystems) while our sandbox code controlled feeding each subsystem relevant simulation information and tying all of the students' code together into the game engine. While care was taken when designing the sandbox environment, not unexpectedly, once the students were able to dig in and start poking around, they quickly uncovered numerous edge-cases and either "broke" the API we made for them or uncovered important gaps in the documentation we had provided them. Like any software project, iteration and testing of the activity itself will prove invaluable for future iterations. In future, the activity might benefit from having more subsystems per ship, but the constraint of having each subsystem at least partially interconnected with multiple other subsystems may make adding each new subsystem increasingly difficult.

The sandbox environment that was built for this activity was a significant undertaking from the perspective of personnel. Two full-time undergraduate co-op students devoted over a month of their work term to developing the main features of the sandbox. This development was overseen by a $\mathrm{PhD}$ student with significant experience developing in Unity. Many people, including the SE 101 course instructors, have contributed to its development leading up to the 2018 pilot implementation of the activity, and in the time since. Currently, development of the spaceship sandbox is ongoing, and will continue until the next offering in fall 2019.

The most significant issue faced during this activity for the teaching team was students leaving the activity early (or not showing up at all). While it is difficult to say what drove those students away, at least some left out of frustration for the task (as seen with Student 2's partner). There were also issues with the physical space used, the significant number of hours (and effort) required to successfully complete the activity, and for some groups, a breakdown in teamwork. While it is possible that attaching additional grades to the activity could create enough extrinsic motivation to get students to stay, it is hard to say how engaged those students will be if that is all that keeps them in the activity. A number of suggested changes for the next offering (described in section 5 below) seek to mitigate the weaknesses of this activity, but careful monitoring will be required to see if the problem persists in the future. 


\section{RECOMMENDATIONS FOR FUTURE ITERATIONS}

The feeling from both observers of the activity, and from students, was that the activity has value, and should continue in the future. The feedback collected in fall 2018 point to a number of tweaks, both big and small, that will improve the activity for the future. A classroom computer lab was used for the activity as it was a room that the students were familiar with, and that would have Unity pre-installed. Unfortunately, this room has a very awkward setup if students are working in groups larger than three students, and because the students preferred to work on their laptops anyways, the advantages of this room were effectively removed. For the fall 2019 offering, students will be instructed to preinstall Unity and Git on their own laptops, and the activity will take place in the Engineering Ideas Clinic space at Waterloo. This room can hold 240 students at a time, and is a large active learning classroom with reconfigurable tables designed for groups of four students to collaborate. Using this space will remove many of the physical hurdles of collaborating in such large teams.

For fall 2019, the activity will also be split across three work periods, instead of two. From Table 1, there are three development steps for each sub-system (with the exception of Sensors, which will need to be made slightly more complex), that slowly increase in complexity as students progress through the activity. Splitting the activity across three work periods gives a natural objective for each day, clarifies when students should rotate between sub-systems, and will reduce the energy burden each day. This change will provide students with more clarity around tasks, and the expected pace of development, and provides an opportunity to add additional checkpoints to better identify struggling students to the course teaching team. This will allow interventions with these student(s) to ensure they are making forward progress, and are not becoming too frustrated with the task.

Following from the student recommendations, the list of teams will be made available before the activity begins to give students a chance to meet each other and discuss their goals for the activity. This early teambuilding could be done in a formal, structured setting, like the Ideas Clinic teamwork workshops (see [10] [11] [12] for additional description of these), or could be left up to the students. While there are significant benefits to conducting this team-building in a formal setting, scheduling may become too burdensome. In either case, this will provide the students additional opportunity to meet their classmates before the pressure of the activity itself.

The last recommendation that is being considered for fall 2019 is to provide additional supporting documentation for students who are interested in learning more, or who are struggling during the activity. While there are obvious benefits to this, the course instructors are cognizant of student time. Some students, in their drive to learn more and be better, may devote too much time to learning content that is not formally a part of their curriculum. While this might benefit them as software engineers, it could come at the cost of their other 1A courses. Speaking more narrowly about tutorials on how to configure Unity and/or Git, these already exist in various forms at Waterloo, and online, and so could easily be provided to students. In this case, the boost in speed at the start of the event is likely worth the effort on the part of both students and instructors.

\section{CONCLUSIONS}

The Engineering Ideas Clinic, with instructors and program administration in the Software Engineering program at the University of Waterloo developed a twoday Engineering Design Days activity to introduce first year Software Engineering students to multi-person development of multi-version software. This activity required students to work in teams of 16 , split across four sub-groups of four students, to design, test, and integrate sub-systems for a digital spaceship. To complete this task, students interacted with a custombuilt "spaceship sandbox" in Unity, and collaborated using Git, two popular tools in software engineering.

This activity had six learning outcomes:

1. version control software (using Git);

2. prototyping theory;

3. division of labour for large tasks;

4. managing variants of software;

5. pair programming; and

6. quickly learning an unfamiliar API.

In data collected from students through an online survey, and an in-person focus group, the activity was successful in four of these outcomes: version control, division of labour, managing variants of software, and learning an unfamiliar API. These data showed that students generally enjoyed the activity. These data also provided a number of constructive recommendations for improving future offerings of the activity. Development of the activity and its sandbox environment is ongoing, and currently this activity is planned to run again in the fall 2019 term with the next incoming class of Software Engineering students.

CEEA19; Paper 131

University of Ottawa; June 9-12, 2019

-7 of $8-$ 


\section{Acknowledgements}

The authors would like to acknowledge the support of the NSERC Chair in IDEAs for supporting the development of this activity.

\section{References}

[1] A. Hurst, C. Rennick and S. Bedi, "A 'Lattice' Approach to Design Education: Bringing Real and Integrated Design Experience to the Classroom Through Engineering Design Days," in International Conference on Engineering Design (ICED 19), Delft, 2019 (accepted).

[2] P. Frise, G. Rohrauer, B. Minaker and W. Altenhof, "Identifying the Design Engineering Body of Knowledge," in International Conference on Engineering Design (ICED), Stockholm, 2003.

[3] I. Ivkovic, T. L. Willett, M. J. Borland and M. Gorbet, "Design Days Boot Camp: Enhancing Student Motivation to Start Thinking in Engineering Design Terms in First Year," in CEEA Annual Conference, Toronto, 2017.

[4] E. Li, C. Rennick, C. Hulls, M. Cooper-Stachowsky, E. Boghaert, M. Robinson, W. Melek and S. Bedi, "Tron Days: Horizontal Integration and Authentic Learning," in CEEA Annual Conference, Toronto, 2017.

[5] S. Phillips, K. Geisinger, R. Al-Hammoud and S. Walbridge, "Enhancing Student Learning by Providing a Failure Risk-Free Environment and Experiential Learning Opportunities," in ASEE Annual Conference, Salt Lake City, UT, 2018.

[6] C. Rennick, C. Hulls, D. Wright, A. J. Milne, E. Li and S. Bedi, "Engineering Design Days: Engaging Students with Authentic Problem-Solving in an Academic Hackathon," in ASEE Annual Conference, Salt Lake City, UT, 2018.
[7] D. Parnas, "Software engineering or methods for the multi-person construction of multi-version programs," in IBM 1974: Programming Methodology. Lecture Notes in Computer Science, Berlin, Springer, 1974, pp. 225-235.

[8] H. Lichter, M. Schneider-Hufschmidt and H. Zullighoven, "Prototyping in Industrial Software Projects -- Bridging the Gap Between Theory and Practice," IEEE Transactions on Software Engineering, vol. 20, no. 11, pp. 825-832, 1994.

[9] Unity Technologies, "Unity for Education," [Online]. Available: https://unity.com/education. [Accessed 30 April 2019].

[10] E. Jobidon, M. Barichello, R. Al-Hammoud, M. Mostafapour, C. Rennick, A. Hurst and J. Grove, "Building Engineering Professional and Teamwork Skills: A Workshop on Giving and Receiving Feedback," in ASEE Annual Conference, Salt Lake City, 2018.

[11] A. Hurst, E. Jobidon, A. Prier, T. Khaniyev, C. Rennick, R. Al-Hammoud, C. Hulls, J. Grove, S. Mohamed and S. Bedi, "Towards a Multi-Disciplinary Teamwork Training Series for Undergraduate Engineering Students: Development and Assessment of Two First-Year Workshops," in ASEE Annual Conference, New Orleans, 2016.

[12] R. Al-Hammoud, A. Hurst, A. Prier, M. Mostafapour, C. Rennick, C. Hulls, E. Jobidon, E. Li, J. Grove and S. Bedi, "Teamwork for Engineering Students: Improving Skills Through Experiential Teaching Modules," in CEEA Annual Conference, Toronto, 2017.
CEEA19; Paper 131

University of Ottawa; June 9-12, 2019
-8 of 8 - 